\title{
Synoptic Analysis of Cold Air Outbreaks over the California Central Valley ${ }^{\mathscr{A}}$
}

\author{
RICHARD GROTJAHN AND RUI ZHANG \\ Atmospheric Science Program, Department of Land, Air, and Water Resources, \\ University of California Davis, Davis, California
}

(Manuscript received 16 March 2017, in final form 29 July 2017)

\begin{abstract}
How does extreme cold air reach the California Central Valley (CCV) and most of the U.S. west coast? This question is answered using composite patterns for the 10 coldest cold air outbreaks (CAOs) to reach the CCV during 1979-2013. While unusually cold air over California occurs in all events by design, how it arrives there is complicated and varies. The only other feature present in all events for several days prior to CAO onset is unusually strong surface high pressure in and south of the Gulf of Alaska. This high has low-level cold air on its west side and a deep layer of cold air moving southward on its east side. Cold air aloft flows parallel to the North American west coast and sinks as it approaches the CCV. Farther west, warm advection builds a ridge aloft. The large-scale meteorological pattern (LSMP) is equivalent barotropic. The LSMP's ridge over Alaska, trough near California, and ridge over the southeastern United States appear in all cases by onset and resemble the Pacific-North American teleconnection pattern. Cross sections show cold air flowing from the continental interior consistent with a strong pressure gradient created by extreme cold in the continental interior. Where and when the interior cold and surface flow occurs varies between events. A geopotential height trough associated with that cold air aloft passes over the CCV before onset fostering sinking behind that is reinforced by the cold air advection below. Although sinking, as a locally defined anomaly, the cold intensifies as it migrates from the polar region to the climatologically warmer $\mathrm{CCV}$.
\end{abstract}

\section{Introduction}

Extreme cold air outbreaks (CAOs) have created multibillion dollar losses in the state of California. Especially hard hit have been agricultural operations in the California Central Valley (CCV). The large societal and economic consequences of CAOs in the CCV and elsewhere motivate investigations of CAOs in different regions of the world. Extreme CAOs advect strongly cold air into a region that lengthens the time of excessive cold during the day; longer duration is linked to greater economic consequence. Some studies focus on the performance of model simulations and statistical analyses of CAOs (e.g., Whan and Zwiers 2016; Whan et al. 2016), the climatology of CAOs over North America, including the behavior of CAOs in the past (e.g., Portis et al. 2006) and under future climatic conditions (e.g., Vavrus et al. 2006; Wheeler et al. 2011), and the

\footnotetext{
Supplemental information related to this paper is available at the Journals Online website: https://doi.org/10.1175/JCLI-D-170167.s1.

Corresponding author: Richard Grotjahn,grotjahn@ucdavis.edu
}

atmospheric circulation patterns associated with CAOs that could be used to evaluate the simulation and prediction ability of climate models (Loikith and Broccoli 2012). Other studies emphasize the interaction between the low-frequency modes and the synoptic features associated with the extreme temperature events (e.g., Konrad 1998; Cellitti et al. 2006; Westby and Black 2015; Carrera et al. 2004) and principal modes of variability (Quadrelli and Wallace 2004). However, Loikith and Broccoli (2014) do not find a connection between California cold outbreaks and either El Niño-Southern Oscillation or the northern annular mode; they do find a link with the negative Pacific-North American (PNA) pattern and a tendency for more cold days over western North America. Although it is outside the scope of this article, the PNA pattern has a notable correlation with our large-scale meteorological pattern's (LSMP's) ridge-trough-ridge pattern.

Some related works focus on the generation of surface anticyclones associated with CAOs. Anticyclones associated with CAOs are "cold" (in contrast to the "warm" subtropical high). However, the cold high is not necessarily centered on the coldest air as the circulation around the high may contribute to cold air advection on 
its leading side (often the eastern and southern sides). Dallavalle and Bosart (1975) investigated a half dozen cold surface anticyclones originating in northwestern Canada from a half dozen winters. They grouped the events into two types based on factors like the path and speed the anticyclone moved. They also review the link between cold temperatures and cold anticyclones and upper-level vorticity equation terms. The surface anticyclone lies between a downstream trough and upstream ridge at upper levels so negative vorticity advection and cold air advection force sinking ahead of the high and contribute to its propagation. Colucci and Davenport (1987) also note that northwestern North American anticyclones are downstream of upper-tropospheric ridges and preceded by a CAO. The sinking will create adiabatic warming by compression that can oppose the temperature change from cold air advection. Konrad and Colucci (1989) separate the CAOs into two types based on different factors than Dallavalle and Bosart (1975); Konrad and Colucci (1989) use the spatial extent of the CAO, whether cyclogenesis is favored ahead of or behind the anticyclone, and whether advection dominates (initially) the adiabatic compression. The factors mentioned include 1) upstream ridge location, 2) cold air and cold air advection location, 3) sinking relative to the sea level pressure (SLP), and 4) cold anomaly surviving even with considerable sinking, all of which are prominent features of the west coast CAOs shown here.

Walsh et al. (2001) use reanalysis data to catalog extreme cold outbreaks affecting the central, east, and Gulf of Mexico coast regions of the United States during 1948-99. They include SLP composites and trajectory analyses showing cold anticyclone location and sinking, properties discussed below. They also include two regions in Europe and consider North American Oscillation (NAO) and Arctic Oscillation (AO) indices prior to $\mathrm{CAO}$ onset in the regions.

Grotjahn and Faure (2008) applied a compositing technique to identify the key parts of the continentalscale LSMPs for extreme events including CAOs. They found that CCV "hard freezes" are associated with the ridge-trough-ridge pattern spanning the Alaska region and the western and southeastern United States in both the geopotential height and thermal fields. Konrad (1996) shows LSMPs of surface temperature and pressure and 500-hPa geopotential height composited for scores of CAOs affecting part of the southeastern United States. Loikith et al. (2017) find LSMPs using 12 self-organizing maps (SOMs). They find two SOMs corresponding to widespread strong cold over the northwestern United States. Xie et al. (2017) use cluster analysis to identify the three highest LSMP patterns (in a hierarchy of patterns) for extreme cold waves affecting three regions of the conterminous United States. Xie et al. find a ridge-trough-ridge LSMP of $500-\mathrm{hPa}$ heights for each of their three cold waves. However, as pointed out in Grotjahn et al. (2016), current knowledge about the synoptic and dynamical mechanisms leading to the associated LSMPs is incomplete. This study examines how the CAO and its associated LSMP develop prior to event onset.

The definition of the CAOs in the present study is different from that of hard freezes in Grotjahn and Faure (2008). We use surface minimum temperature anomalies at multiple surface stations in the CCV plus the 700-hPa temperature anomaly at National Weather Service radiosonde network station KOAK (Oakland International Airport) to isolate events, whereas they use the total field of minimum temperature and subsequent maximum temperature from only one station (Executive Airport in Sacramento) to identify events. However, the purpose of including the $700-\mathrm{hPa}$ temperature anomaly at KOAK in the present study and the subsequent maximum temperature in Grotjahn and Faure (2008) is the same: selecting for situations in which strong cold air advection dominates rather than strong near-surface radiational cooling.

Like Grotjahn and Faure (2008), we use the bootstrap statistical tool to identify significant regions in the LSMPs. Unlike Grotjahn and Faure (2008), this work centers around the development of the three-dimensional synoptic structures associated with CAOs. The LSMPs consist of surface-level features (i.e., temperature anomalies, sea level pressure, and surface winds), synoptic patterns of geopotential height anomalies (500 and $1000 \mathrm{hPa})$ and temperature anomalies $(700 \mathrm{hPa})$, vertical synoptic structures of winds and temperature anomalies shown in vertical cross sections, and backward trajectories analysis. In short, we intend to tell a complete and compelling synoptic story about CAOs over the CCV.

The data and methods used to isolate and investigate the extreme CAOs are described in the next section. Section 3 examines synoptic structures and the evolutions of the LSMPs associated with the CAOs. Conclusions and discussion are presented in section 4.

\section{Data and methods}

\section{a. Data}

The CAO events are isolated from daily surface minimum temperature values at 17 National Climatic Data Center (NCDC) stations located across the CCV. The 700-hPa temperature at radiosonde station KOAK is also used to exclude cold events mainly induced by 
strong near-surface radiational cooling in favor of events with extreme cold in much of the lower troposphere. The events favored have strong cold air advection in addition to nocturnal radiational cooling.

The synoptic analyses are based on National Centers for Environment Prediction (NCEP)-National Center for Atmospheric Research (NCAR) Reanalysis-1 (NNRA1) dataset (Kalnay et al. 1996). The spatial and temporal resolutions are respectively $2.5^{\circ} \times 2.5^{\circ}$ and 4 times daily. The data used include 62 boreal winters (1 December-28 February) from 1951 through 2013. However, we focus upon the coldest events occurring after 1978 in this report. The European Centre for MediumRange Weather Forecasts (ECMWF) interim reanalysis (ERA-Interim; Dee et al. 2011; http://apps.ecmwf.int/ datasets/data/interim-full-daily/), downloaded at much higher resolution, $0.25^{\circ} \times 0.25^{\circ}$, is used to cross check the three-dimensional backward trajectories.

\section{b. Methods}

\section{1) EVENT ISOLATION AND RANKING}

Prior studies used various definitions of what is a CAO; Wheeler et al. (2011) summarize several CAO definitions and add one of their own in their climatology of North American CAOs for model and reanalysis data. We use station data in combination with $700-\mathrm{hPa}$ temperature anomalies to identify CCV CAOs. Our procedure for isolating $\mathrm{CAO}$ events is similar to that described in Lee and Grotjahn (2016). Full details can be found in Zhang (2016) and Grotjahn (2011).

First, "raw" values of the long-term daily mean (LTDM) of daily surface minimum temperature (Tmn) are calculated by averaging the 63 values from January 1951 to December 2013 at each of 17 CCV stations. Second, these 365 daily raw values have an unacceptable variation over nearby days of $\pm 1 \mathrm{~K}$. To remove this variation, harmonics were found by Fourier transforming these raw data. After comparing summations of the first several harmonics, we concluded that an LTDM composed of the first five harmonics obtained the "smoothed" LTDM for each station that we sought. Long-term daily mean standard deviation (LTDMSD) of Tmn is calculated for each station using the corresponding smoothed LTDM. The LTDMSD has no consistent variation over the season so the winter average is used. The Tmn-LTDM anomaly found each day of the 62 winters (December 1951-February 2013) is normalized by the LTDMSD to obtain a normalized daily surface minimum temperature (NmTmn) for each station. When two consecutive dates are among the coldest $5 \%$ of NmTmn values at $\geq 9$ stations, a "candidate" event is identified. A candidate event becomes a CAO if
TABLE 1. Onset date and rank of the strongest 10 CAOs during 1979-2013.

\begin{tabular}{cl}
\hline \hline CAO event rank & Onset date \\
\hline 1 & 21 Dec 1990 \\
2 & 5 Feb 1989 \\
3 & 12 Jan 2007 \\
4 & 21 Dec 1998 \\
5 & 16 Jan 2012 \\
6 & 27 Feb 2011 \\
7 & 30 Jan 2002 \\
8 & 8 Dec 2009 \\
9 & 13 Jan 2013 \\
10 & 16 Jan 1987 \\
\hline
\end{tabular}

the 700-hPa temperature anomaly at $\mathrm{KOAK}$ is $<-0.5^{\circ} \mathrm{C}$ on the onset day. This threshold identifies a CAO with cold through at least a $300-\mathrm{hPa}$ depth of the lower troposphere and excludes cold events with strong, shallow, nighttime radiative cooling that are not CAOs.

Hartmann and Wendler (2005) investigated the significance of the 1976/77 climate shift, when the Pacific decadal oscillation (PDO) index shifted from dominantly negative values during 1951-75 to dominantly positive values during 1977-2001, upon the climatology of Alaska. Their time means of several variables (i.e., temperature, wind, sea level pressure, and geopotential height) are distinctly different between the two time periods. Cassano et al. (2011) also showed the temperature increase after 1976 over Alaska due to this climate shift. As we use composites, we prefer to group the CAOs into two groups (before and after the start of 1979). One reason is to avoid the impact of this climate shift on our synoptic analysis. Another reason is the well-known (e.g., Kalnay et al. 1996) impacts of increased satellite-based observations after 1978 upon reanalyses, especially upper-air observations. Thus, the full 63 years establish better the LTDMs for CCV stations, but only the strongest 10 CAO events after 1979 (Table 1) are studied here.

\section{2) BACKWARD TRAJECTORIES}

Dallavalle and Bosart (1975) and Konrad and Colucci (1989) found more than one type of cold anticyclone or CAO. Backward trajectories used by Lee and Grotjahn (2016) to track events prior to extreme summertime heat events found two distinct types. Thus we examine trajectories to see if there are distinct groups of CAOs based on how they evolve. However, no clear grouping is apparent. Hence, backward trajectories are included to show complex three-dimensional paths of the cold air reaching the lower troposphere above the $\mathrm{CCV}$ at each CAO onset. Six parcels, initially at gridpoint locations $39^{\circ} \mathrm{N}, 122^{\circ} \mathrm{W} ; 40^{\circ} \mathrm{N}, 122^{\circ} \mathrm{W} ; 37^{\circ} \mathrm{N}, 121^{\circ} \mathrm{W} ; 38^{\circ} \mathrm{N}, 121^{\circ} \mathrm{W}$; 


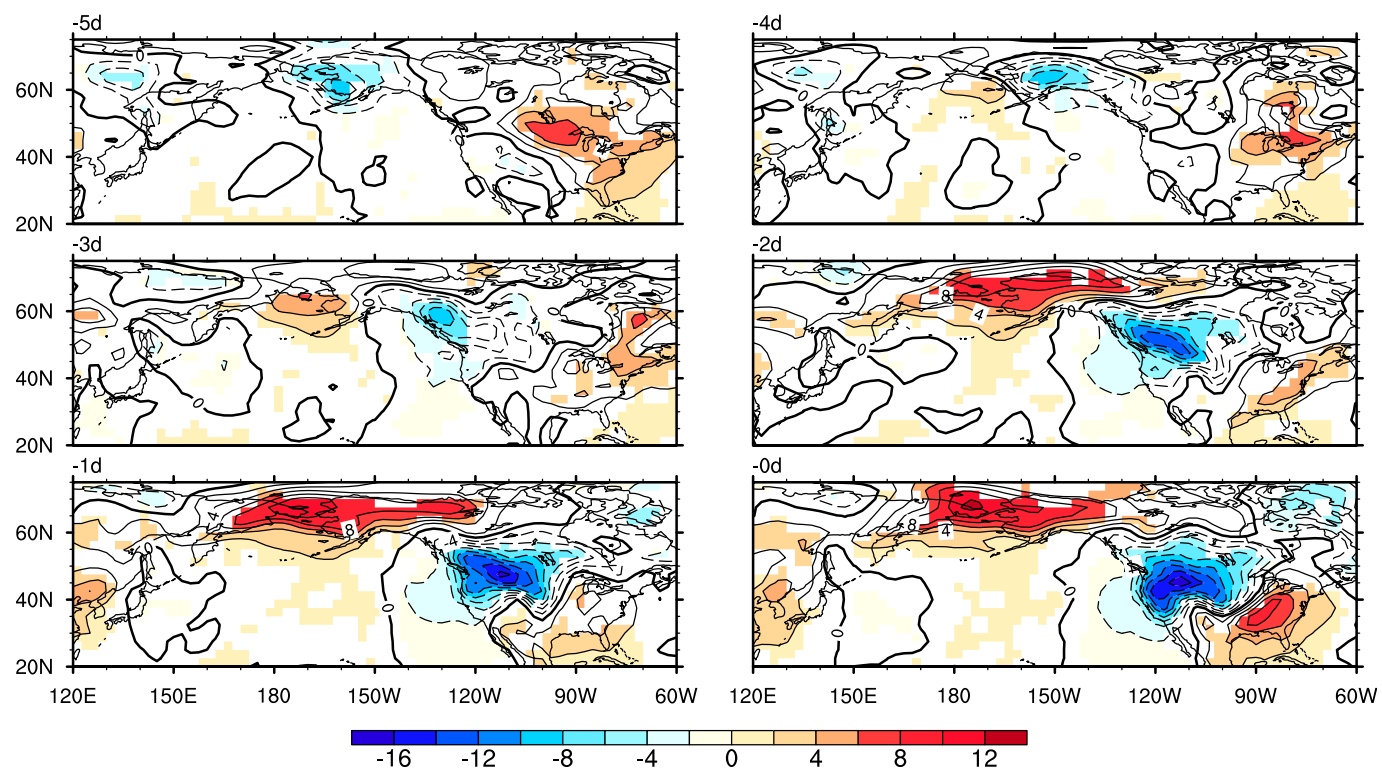

FIG. 1. Composites of the 10 CAOs for surface temperature anomaly at sigma level 0.995 for days before onset. The label $-N \mathrm{~d}$ in the top-left corner of each panel denotes $N$ days prior to onset (all times are at 1200 UTC). Grid points where absolute values of sign count are greater than 3 are shown in shaded color. The contour interval is $2^{\circ} \mathrm{C}$.

$36^{\circ} \mathrm{N}, 120^{\circ} \mathrm{W}$; and $37^{\circ} \mathrm{N}, 120^{\circ} \mathrm{W}$ are combined to form a mean trajectory for each event.

Backward trajectories are calculated from NNRA1 data using the procedures in Lee and Grotjahn (2016). More details can be found in Zhang (2016). Trajectories for the four strongest events from ERA-Interim data were also calculated and no appreciable difference was found from NNR1 results shown here.

\section{3) LEAD-LAG COMPOSITES}

Composites are calculated for either the anomaly or total fields at fixed times prior to each event onset to understand the evolution of the LSMPs. Consistency between the 10 events is measured by the sign count (Grotjahn 2011) at each grid point. The sign of the anomaly field is found for each event and those signs are summed to get the sign count. In other words, the number of events with negative sign at a grid point is subtracted from the number of events with positive sign at that grid point. Thus, a sign count of 10 here means all events at that grid point have positive anomaly; absolute values of sign count greater than 3 mean at least 7 of the 10 events have the same sign of anomaly at that location. Besides sign count, the bootstrap statistic method is used to measure the significance of values at each grid point and hence identify statistically significant parts of the LSMPs (Grotjahn and Faure 2008). The bootstrap is a nonparametric way of comparing a given ensemble average with ensemble averages from randomly drawn dates at the same location. The value of the 10-CAO ensemble mean is compared to the distribution of values from 1000 randomly drawn 10-member ensembles at each grid point. The bootstrap method compares the $\mathrm{CAO}$ ensemble mean value to the random member distribution to obtain a percentage for the CAO mean relative to the range of randomly drawn ensembles' mean values.

\section{Results}

\section{a. Surface structures}

Composites of surface air temperature anomaly are shown in Fig. 1. These 10-event composites have a significant temperature ridge-trough-ridge pattern over Alaska, the west coast, and the southeastern United States. The noticeable cold air anomaly over Alaska five days prior to the onset strengthens as it moves southeast, then southward, reaching the CCV at onset. The composites also reveal a warm air anomaly over the Bering Sea four days before onset that spreads both east and west, reaching a maximum value $\left(12^{\circ} \mathrm{C}\right)$ at onset. A third anomaly has unusual warmth in the southern and eastern United States. Compared with the cold anomaly, the southern and eastern U.S. warm anomaly tends to be more stationary.

While the composite shows the warm and cold anomalies amplifying greatly over the period shown, part of that change results from the individual events 


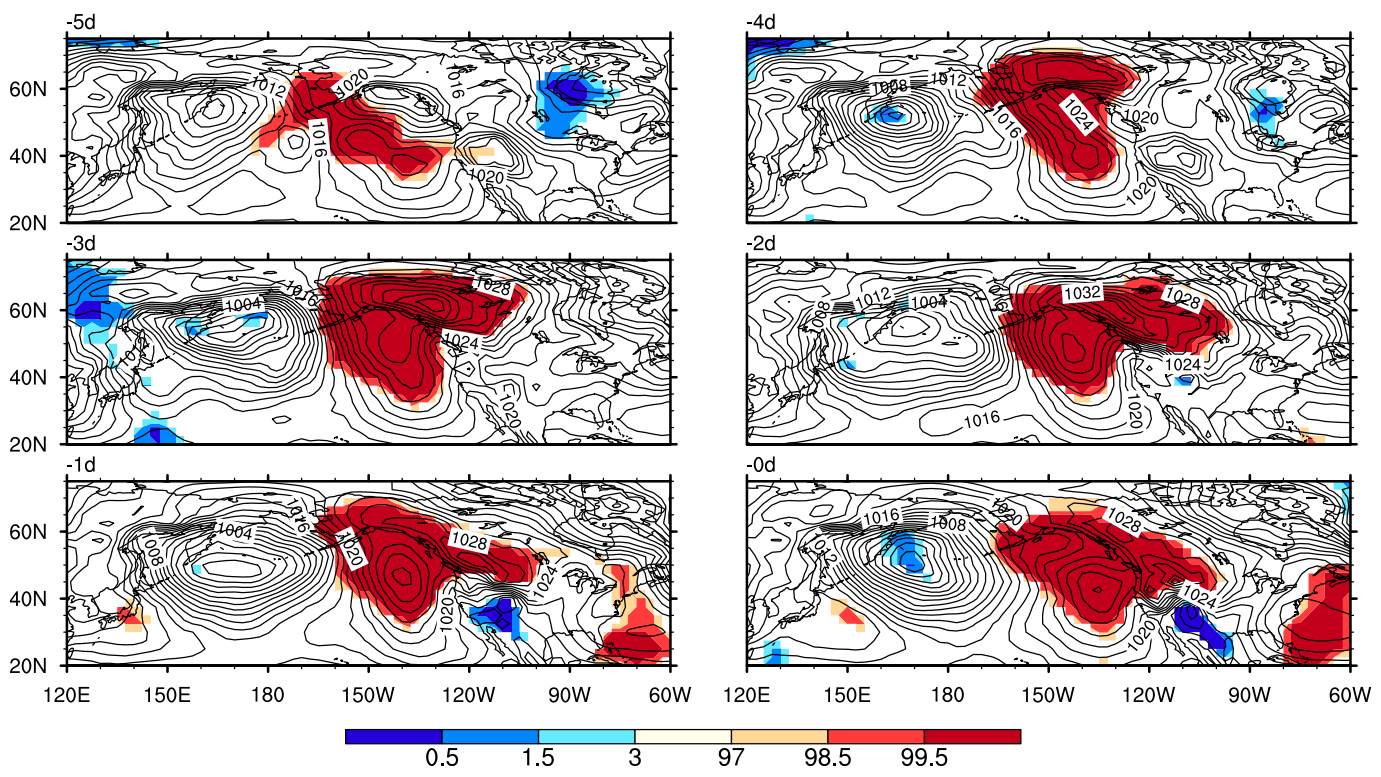

FIG. 2. Composites of 10 CAOs for sea level pressure. The labels are as in Fig. 1 showing days at and prior to onset (all times are at $1200 \mathrm{UTC}$ ). Shading denotes significance level. Contour interval is $2 \mathrm{hPa}$.

being progressively more in phase as onset is approached. Hence, while the composite cold anomalies decrease $-4^{\circ} \mathrm{C}$ day $^{-1}$ over two consecutive days (days -2 and -1 ), that rapid a change is generally not seen during the individual events. (Individual event sequences are in the supplemental material.) Further, the noticeable enlarging of the cold anomaly area before onset in Fig. 1 varies a lot between events. Similarly, the composite warm anomaly near Alaska has large change in peak value $\left(4^{\circ} \mathrm{C}\right.$ day $\left.{ }^{-1}\right)$ and areal extent at day -2 . Individual events evolve as follows. Eight of the 10 events have unusual warmth across the Bering Sea with the time of the initial presence of this warmth varying between events from five days to two days before the onset; the two exceptions are events 5 and 7 (Table 1), where there is a warm anomaly farther west and farther east, respectively. The warmth expands for 8 of the 10 events into northwestern Canada; the exceptions are events 5 and 7 . Most of those 8 events have the anomalous warmth expanding eastward across much of the Canadian Arctic by the onset (events 6 and 9 only extend the warm anomaly into northwestern Canada). Nine of the 10 events have a cold anomaly in Alaska that expands southward and eventually part of that anomaly reaches the CCV; event 9 is the exception, whose cold anomaly is part of a cold anomaly in Canada. Event 9 is also the one exception to the cold anomaly developing a horseshoe shape, in which the anomaly extends farther south along the west coast and high plains than over the Rockies. All but event 8 have a prominent warm anomaly in the southeastern United States by onset (the warm anomaly is over the southern Rockies and northeastern
Mexico for event 8). The warm anomaly is strong over an area large enough to include the Midwest in 7 of those 9 events. In most events this warm anomaly amplifies in place in states bordering the Gulf of Mexico during the final two days before onset. Day -2 is the first day that most events ( 7 out of 10 ) have the ridge-trough-ridge (Alaskan region and western and southeastern United States) surface temperature pattern in place with the number of events which have the similar LSMPs increasing to all 10 events at onset. In contrast, only one event has the ridge-trough-ridge in place at day -3 , and hence that pattern is not present in the composites (Fig. 1) until day -2 . In short, most events follow a similar evolution, with events $5,7,8$, and possibly 9 having differences in some of the properties.

The cold surface temperature anomaly extends off the west coast of North America. It is not surprising that the cold anomalies are mostly confined to land area since strong surface heat fluxes will quickly reduce the anomaly when cold air blows over warmer ocean (e.g., Grotjahn and Wang 1989). Over the continent the minimum decreases from $-8^{\circ}$ to $-16^{\circ} \mathrm{C}$ over day -4 to the onset, whereas the cold anomalies over the ocean are mostly between $-2^{\circ}$ and $-4^{\circ} \mathrm{C}$ during the same period. Although it is not as large a temperature anomaly as over the adjacent continent, this oceanic cold surface air temperature anomaly is crucial in forming an unusually strong SLP high in and south of the Gulf of Alaska (Fig. 2).

Figure 2 shows the ensemble average SLP evolution for the 10 events. The Aleutian low is west of its climatological position. As onset is approached, this low 

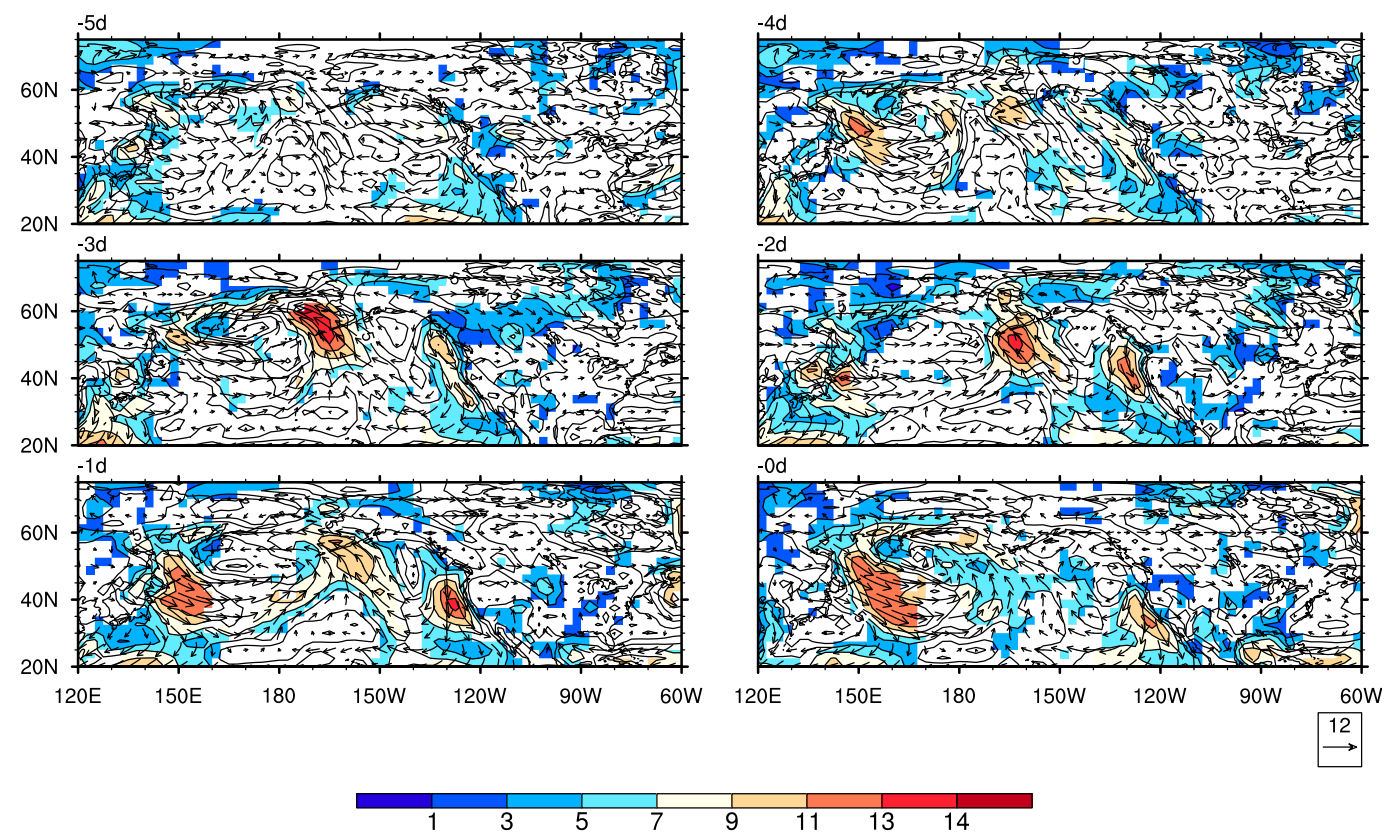

FIG. 3. Composites of 10 CAOs for surface wind. The labels are as in Fig. 1 showing days at and prior to onset (all times are at 1200 UTC). Contours indicate the speed of the wind. The contour interval is $2 \mathrm{~m} \mathrm{~s}^{-1}$. Meridional wind is used to calculate the sign count. Grid points where absolute values of sign count are greater than 3 are shown in shaded color.

intensifies in place (growing larger in area, including toward the west coast of Alaska and deepening in central SLP anomaly). The intensification of the parent Aleutian low in the composites is due to individual event patterns becoming both more in phase and to shortwave troughs along the parent low's sides. As noted in Fig. 1, there is a warm anomaly over Alaska and the Bering Sea that develops from day -3 to the onset where there is strong SLP low pressure. Individual event sequences are shown in the supplemental material.

Anomalously high SLP occurs over the coldest surface air over the western continent and also near and south of the Gulf of Alaska. Over day -4 to the onset, the center of the high of sea level pressure over the cold interior of western North America (Fig. 2) moves southeastward, matching well the motion of the cold anomaly (Fig. 1). Although the cold anomaly over the eastern Gulf of Alaska and to the south is relatively small, its position is quite consistent with that of the unusual high sea level pressure off the west coast. The oceanic SLP high exceeds $1030 \mathrm{hPa}$ for several days prior to onset. Such high SLP is uncommon for an area of climatologically low SLP values. This SLP high does not move as much as the SLP high over the cold interior of western North America. Also, the 1000-hPa geopotential height anomaly field shown later emphasizes this anomalous high of sea level pressure in and south of the Gulf of Alaska with a maximum anomalous height of $200 \mathrm{~m}$ in the same region.
The individual events vary in their SLP pattern. (Individual events are shown in the supplemental material.) The variation is greatest in the low pressure near the Bering Sea. Some events have multiple lows that merge; some keep the lows separate. For some events one or more lows are centered at or south of the Aleutians, for some events the low or lows are centered north of the Aleutians; some events have low centers on both sides of the Aleutians. Events 9 and 10 are odd in developing a SLP trough along the Gulf of Alaska coast.

In contrast, all 10 events have a prominent SLP maximum in the eastern and southern Gulf of Alaska. That SLP high is weakest for event 8 , prominent only on days -4 through -2 . For events 7,9 , and 10 , the oceanic SLP high migrates across the North Pacific, apparently unconnected to higher pressure over the continent (farther east) until just before onset. While the composite has strongest SLP high over western North America, that high is weaker than the one near the Gulf of Alaska maximum in events 6,7, and 9; in event 10 it is stronger (slightly) only on days -4 and -3 . Loikith et al. (2017) find a similar high during northwestern U.S. cold spells.

Returning to the composites, on days -4 and -3 , the continental SLP high creates strong westerlies over northern Alaska that turn northwesterly over the Yukon Territory. On the southeast side of this high, the strong northwestward SLP gradient causes strong northwesterly winds over the Canadian Plains (Fig. 3). Similarly, 
southeast of the Gulf of Alaska SLP high a northwestward gradient drives strong northwesterly winds just off the North American west coast. In between are very strong northward and northeastward SLP gradients near the western U.S.-Canadian border; these are consistent with the observed northeasterly surface winds there. Considering the vectors in Fig. 3 in combination with the temperature anomalies in Fig. 1, the wind pattern drives a portion of the cold anomaly southeastward along the west coast of Canada and the remainder across the interior Pacific Northwest toward the CCV (Fig. 1). The latter is quite apparent in the temperature change from day -2 to -1 in Fig. 1. On day -2 and day -1 , the strong northeastward sea level pressure gradient has slid farther south along the western U.S. coast (Fig. 2) consistent with the easterly and northerly components of the surface wind near California (Fig. 3), which demark and drive the cold air into the CCV.

To the west, southerly winds between the low and high SLP are strongest just south of the Bering Sea on days -3 and -2 (Fig. 3); these winds help build the temperature ridge over Alaska seen in Fig. 1 by inferred warm air advection. These southerly winds are highly geostrophic and strongly parallel with the SLP contours.

The surface winds have large variation between individual events over the land areas. This variation in direction causes the wind speeds over land areas to be quite small in the composites. Key parts of the surface winds are those most closely linked with the CAO occurring over California. The key parts in the composite are the strong northwesterly winds just off the coast of Canada and the western United States, the northeasterly winds near the western U.S.-Canadian border, and offshore flow along the Canadian and U.S. west coast, especially the California coast. As noted in the SLP fields, the high near the Gulf of Alaska was present in all 10 events and so are the strong northwesterly winds just off the coast. There is some variation in the extent of these northwesterlies, sometimes only occurring off the U.S. west coast, oftentimes migrating southward from the Canadian west coast toward the California coast for several days prior to onset. In 7 of the 10 events these northerly winds are present by day -3 , and present in all 10 events on day -2 . So, the consistency in direction between events as well as the speed cause this prominent feature seen in the composites. The northeasterly flow near the western part of the U.S.-Canadian border found on day -2 in the composites is found in only 6 of the 10 events, and develops a day later in a seventh event (event 3). Events 5, 6, and 7 never develop these northeasterlies. The third flow feature emphasizes offshore flow, starting along the Canadian west coast on days $-5,-4$, or -3 in six of the events, then migrating southward and reaching the California coast by day -1 or the onset. Event 7 has this pattern, but with much weaker offshore flows. Events 3, 5, and 9 only have (generally weak) offshore flow over California, with onshore to the north. So there is much cancellation over western Canada and the U.S. Northwest when forming the composites of surface winds.

In summary, the most consistent feature of the events is, obviously, the cold air anomaly over the CCV and much of the U.S. west coast. Another feature common to all events is the SLP high in and south of the Gulf of Alaska. That high drives cold air on its east side southeastward by consistent and often strong northwesterly surface winds just offshore. One might expect the high SLP over the continent to drive cold air toward the CCV but that pattern is barely visible in the composites in part because the timing of that flow over the land areas occurs sooner or later and over wider or narrower latitude ranges in the different events; contrary flows occur at other times, causing much cancellation in the composites.

\section{b. Temperature and geopotential height anomalies}

Composite temperature anomalies representative of the lower troposphere are shown in Fig. 4. The 700-hPa level values are contoured with shading used to denote significance based on a bootstrap testing procedure that compares the composite value at each grid point against the distribution of randomly drawn same-sized ensembles at each point. The areas that are highly significant (larger than $99.5 \%$ ) become larger as time nears the onset, especially the thermal trough over the North American west coast and the ridge over the southeastern United States. Although individual events tend to have smaller areas of high significance than that of the composite, most events have at least one or two parts of the LSMPs passing the significance test. The central extreme value of the west coast temperature anomaly decreases from $-5^{\circ}$ to $-13^{\circ} \mathrm{C}$ as this trough moves into the $\mathrm{CCV}$ from day -5 to the onset. As stated above, features of different events tend to be more in phase as time is closer to the onset making the composite temperature anomalies both statistically more significant and arithmetically larger at onset than times prior to the onset. For example, the central extreme values of the west coast trough are smaller than $-12^{\circ} \mathrm{C}$ in the $\mathrm{CCV}$ for all events at the onset but how that temperature evolved before that time varies a lot between events. To illustrate, the minimum in that trough varies from $-6^{\circ}$ to $-7^{\circ}$ to $-8^{\circ}$ to $-10^{\circ}$ to $-12^{\circ}$ to $-13^{\circ} \mathrm{C}$ over the days from five days to onset. Some of this intensification is due to the events coming into phase and some to the anomaly moving from an area where the cold air is common (small anomaly) to where it is not (larger anomaly) even 

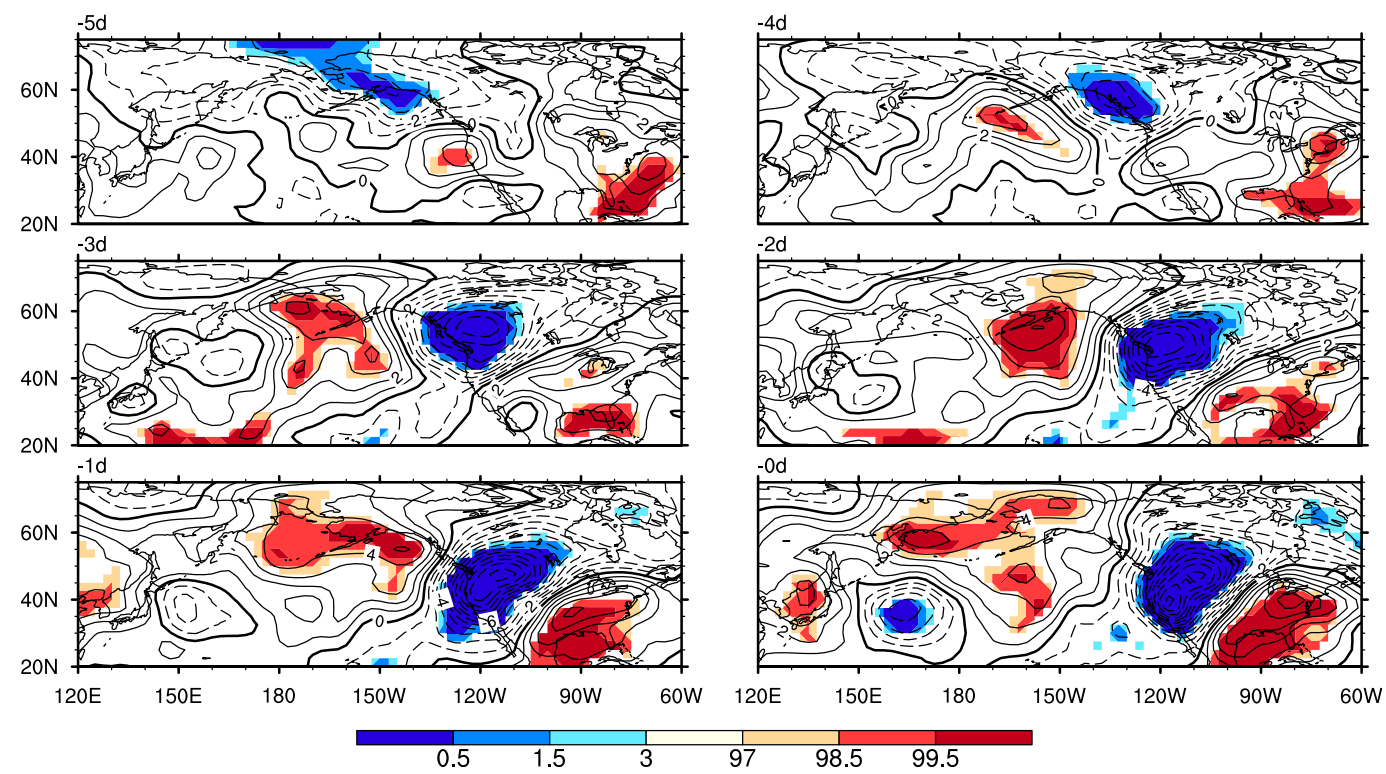

FIG. 4. Composites of the $10 \mathrm{CAOs}$ for anomalous temperature at $700 \mathrm{hPa}$ (contours); shading indicates the significant areas that pass the bootstrap test. Negative values have dashed contours while positive values use solid contours, and the contour interval is $1^{\circ} \mathrm{C}$. The labels are as in Fig. 1 showing days at and prior to onset (all times are at 1200 UTC).

as the air mass is warming. Changes in the minimum temperature of the part of the anomaly affecting the CCV provide a sense of the latter effect. Events where the cold anomaly reaching the CCV area stays over land (events $1,4,8$, and 10 ) have $4^{\circ}-12^{\circ} \mathrm{C}$ decreases in the anomaly minimum. Events where the cold anomaly tracks over the ocean (events 2, 3, 5, 7, and 9) have generally smaller decreases of $0^{\circ}-6^{\circ} \mathrm{C}$. The tracks followed by the cold air that affects the CCV vary quite a bit between events. Some events have an already strong thermal trough moving toward the $\mathrm{CCV}$ while staying over the continent, moving from Alaska eastward, then southward and finally southwestward, whereas some stay over the ocean, either following the North American west coast from Alaska to California (events 2, 3, 5, and 7) or traveling mostly eastward from a cold anomaly well offshore in the Gulf of Alaska (event 9). Some events $(2,6,8$, and 10) have multiple cold centers that interact.

The 1000-hPa anomalous geopotential height composite (Fig. 5) has an amplifying ridge in and near the Gulf of Alaska near the location of the unusual sea level pressure high in the same region (Fig. 2). In Fig. 5 we see how and where that ridge is highly significant. This anomalous ridge expands into western Canada, although the center remains almost stationary near the Gulf of Alaska. A trough at $1000 \mathrm{hPa}$ develops over the southwestern United States becoming noticeable on day -3 and is much weaker than the $500-\mathrm{hPa}$ trough discussed next. A ridge-trough-ridge pattern is apparent at onset and day -1 .

There is a strong equivalent-barotropic component to the height anomalies at 1000 and $500 \mathrm{hPa}$ seen by comparing Figs. 5 and 6. A ridge-trough-ridge pattern (Gulf of Alaska-west coast-southeastern United States) is found in mid- and upper-tropospheric geopotential heights. Composites of $500-\mathrm{hPa}$ geopotential height anomaly shown in Fig. 6 compare favorably with the corresponding hard freezes in the LSMP shown in Grotjahn and Faure (2008) and similar patterns are found for cold in other regions of the United States (Xie et al. 2017). This LSMP becomes apparent and significant from three days prior to the onset in Fig. 6. This highly significant pattern becomes stronger as the onset is neared and has large swaths with statistically significant values greater than the $99.5 \%$ threshold. Parts of the pattern move as onset approaches, more so for the trough. The southeastern U.S. ridge is more stationary as noted for the surface temperature. Similar movements of features of LSMPs with high significance are found in the 700-hPa anomalous temperature field (Fig. 4) as one might expect from the hypsometric equation.

The peak values of the geopotential height anomaly composites of both the Alaskan ridge and southeastern U.S. ridge at $500 \mathrm{hPa}$ (Fig. 6) are much bigger than that at $1000 \mathrm{hPa}$ (Fig. 5) from day -3 to the onset (80-m difference on days -2 and -1 ), leading to an anomalously thicker layer over these two regions, which is 


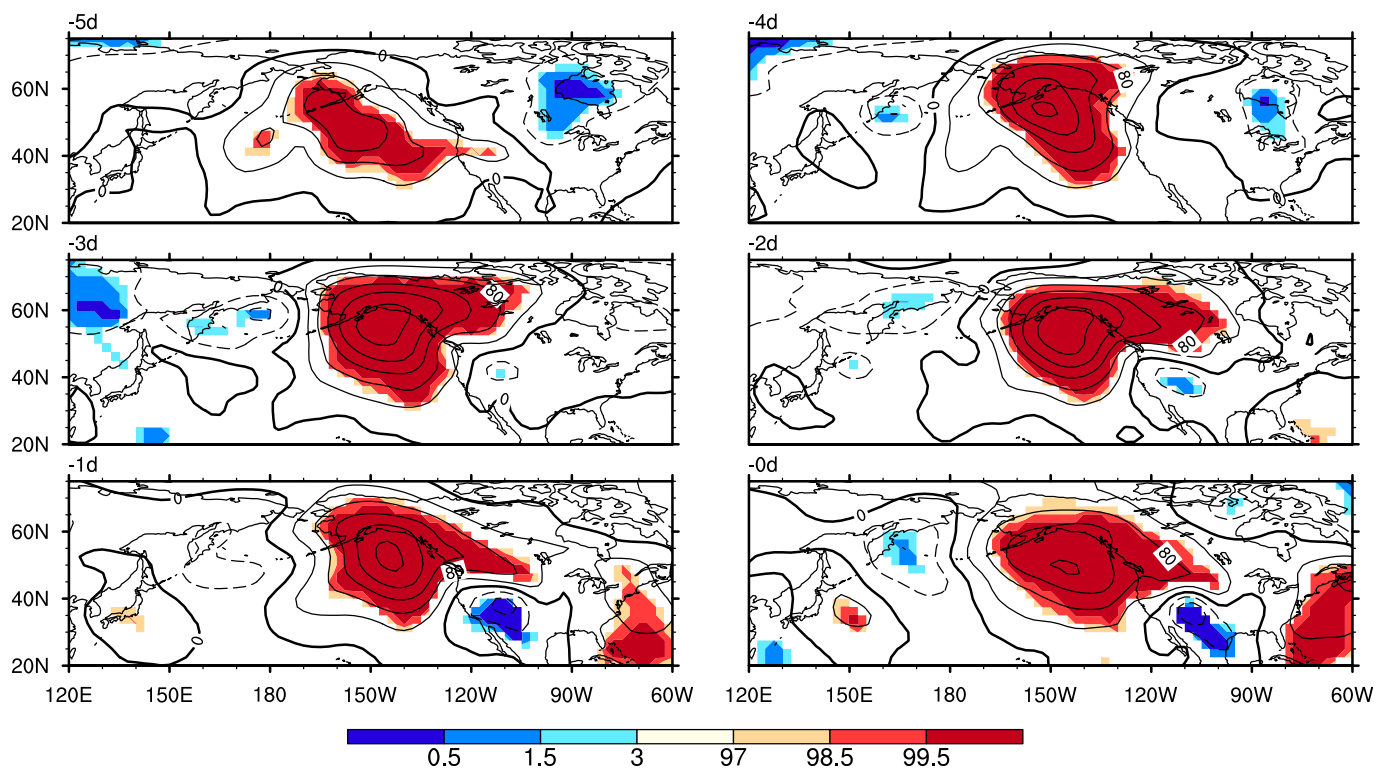

FIG. 5. As in Fig. 4, but for geopotential height anomaly at $1000 \mathrm{hPa}$. Contour interval is $40 \mathrm{~m}$.

consistent with the anomalous higher temperature at $700 \mathrm{hPa}$ in the same regions (Fig. 4). The temperature trough over the western coast is consistent with the trough of the $500-\mathrm{hPa}$ geopotential height field in the same sense.

Both the areas of high significance (larger than $99.5 \%$ ) and the peak values of the geopotential height anomalies of the LSMPs become larger as event onset is approached (Fig. 6). As argued for temperature anomalies at $700 \mathrm{hPa}$, features move at different rates during the different events and thus tend to be more in phase at onset resulting in stronger patterns at later times. However, the patterns of individual events evolve differently. For example, the time when the ridge-troughridge (Alaskan region-west coast-southeastern United States) pattern appears varies from day -4 (events 2 and 7) to the onset (events 5 and 8). The peak value in the trough anomaly decreases by more than $200 \mathrm{~m}$ in some events $(1,4$, and 8$)$ where there is a weak or no trough five days prior to onset. However, the magnitude hardly changes in events $(2,3,6$, and 7$)$ that have a strong trough five days prior. The composite peak value of the

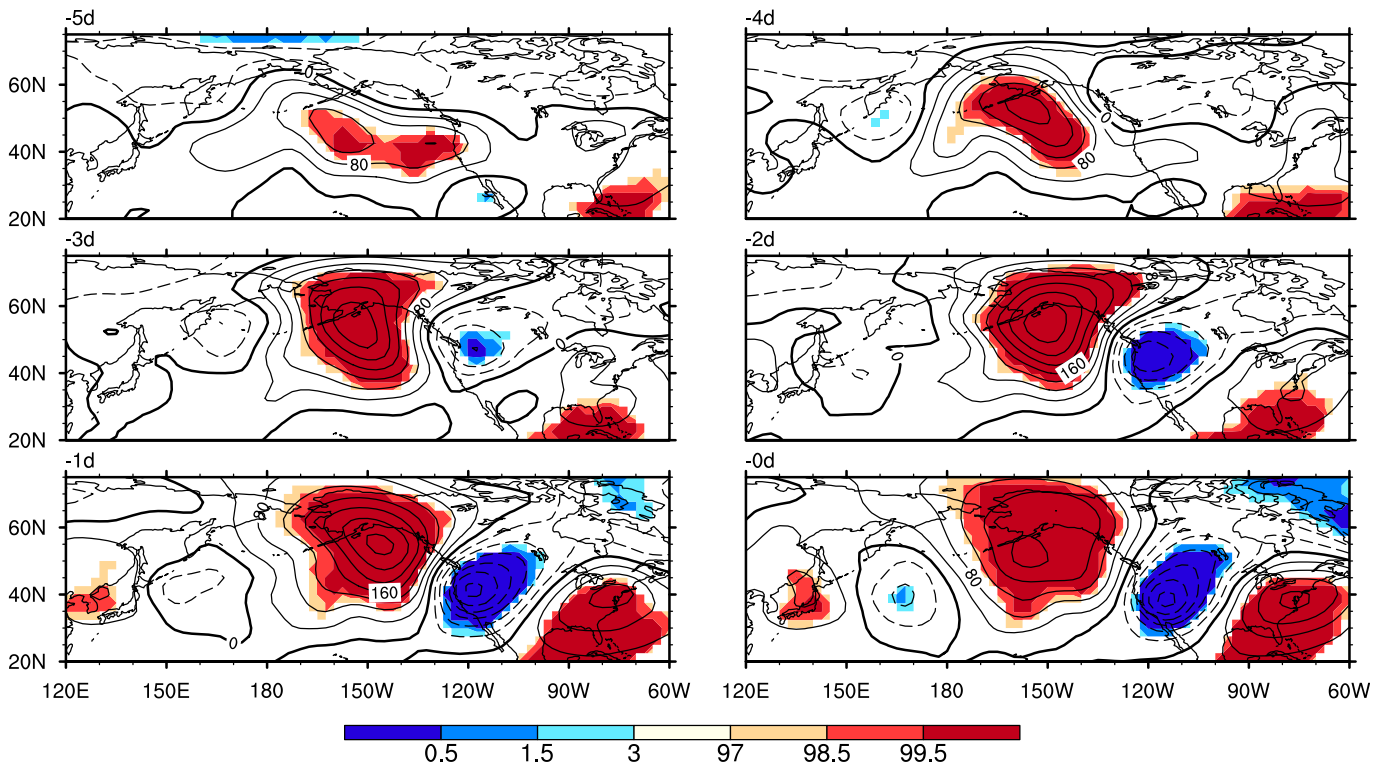

FIG. 6. As in Fig. 4, but for geopotential height anomaly at $500 \mathrm{hPa}$. Contour interval is $40 \mathrm{~m}$. 
southeastern ridge increases gradually from 40 to $160 \mathrm{~m}$ over day -4 to the onset in the composite (Fig. 6) and 7 of the 10 events have the largest magnitude of the southeastern ridge at onset but the changes and ridge anomaly center vary widely between the individual events.

As stated in the introduction, this ridge-trough-ridge pattern looks similar to the PNA pattern. A full investigation of the PNA link is outside the scope of this article, but readers may appreciate these general comments. Some readers may have these concerns: 1 ) the PNA pattern is usually thought of as having a lower frequency that an LSMP, as LSMPs develop and persist for only a few days, 2) the LSMP is similar to the negative sign of the PNA loading pattern, and 3) the PNA trough is $>15^{\circ}$ latitude too far north and the PNA Alaskan ridge $>15^{\circ}$ latitude too far south (and too far west). In response, the time scale may not be sufficiently different (Feldstein 2000, 2002) to concern most readers. Negative signs of the PNA pattern occur frequently. Despite the phase shift, the patterns have notable correlation: -0.49 over a PNA-based domain $120^{\circ} \mathrm{E}-60^{\circ} \mathrm{W}$ and -0.61 over a LSMP-based domain $180^{\circ}-60^{\circ} \mathrm{W}$ (both domains are $20^{\circ}-$ $70^{\circ} \mathrm{N}$ ). Furthermore, Loikith and Broccoli (2014) show a link between the PNA pattern (negative quartile) and percentage of wintertime days with the lowest $10 \%$ of minimum temperatures (primarily western Canada, with lower values over California), and perhaps the PNALSMP phase difference accounts for the disparity. We intend to report more details later in a broader study on dynamical drivers of CCV CAOs.

Finally, it is important to note that the upper trough has passed the CCV by the onset in every event. This implies that negative vorticity advection aloft is an important forcing factor in the sinking motion seen in the trajectories. Loikith et al. (2017) find a similar trough downstream during northwestern U.S. cold spells.

\section{c. Cross sections: Temperature anomaly, meridional (zonal) wind, and vertical wind}

In this section, the three-dimensional structure related to the CAOs will be shown using a series of cross sections in the zonal and meridional planes. (Readers preferring individual event sequences of horizontal wind fields can find them in the supplemental material.) For reference, the CCV is located approximately between $121^{\circ}$ and $123^{\circ} \mathrm{W}$ and between $35^{\circ}$ and $39^{\circ} \mathrm{N}$.

In all the pressure-longitude cross sections (Figs. 7 and 8), persistent rising happens between the low in the western North Pacific and the high near the Gulf of Alaska of Fig. 2, consistent with the southerly winds in the central North Pacific (Fig. 3). This southerly wind and positive temperature anomaly in longitude range $180^{\circ}-$ $150^{\circ} \mathrm{W}$ of Figs. 7 and 8 imply warm air advection in almost the whole layer of 500-1000 hPa. Consequently, the ridge over the Alaskan region builds and the equivalent barotropic pattern seen above is explained. The warm advection is strongest at upper levels on day -2 in all pressure-longitude cross sections. (The supplemental material has additional cross sections at $55^{\circ}$ and $60^{\circ} \mathrm{N}$.)

In Figs. 7 and 8, the sinking is mainly in the eastern part of the sea level pressure high over and south of the Gulf of Alaska where there is also a cold air anomaly (shown in Fig. 1). In Fig. 7, this sinking becomes stronger and shifts eastward as the time nears the onset, which is consistent with the southeastward movement of the core of the sea level pressure high off the west coast (Fig. 2). However, this sinking in Fig. 8 is strongest on day -2 when the oceanic sea level pressure high is strongest and is centered around $50^{\circ} \mathrm{N}, 140^{\circ} \mathrm{W}$. Consistently, as this sea level pressure high moves southward, there is no noticeable sinking in the same longitudinal region on day -1 and the onset in the cross section $5^{\circ}$ latitude farther north.

Northerly winds (approximately east of $140^{\circ} \mathrm{W}$ ) are also found in the east part of the Gulf of Alaska ridge in both the lower and higher levels. This northerly wind is much stronger on day -1 than on day -3 in all the pressure-longitude cross sections, which is consistent with the strengthening of the ridge over Alaska (Fig. 6). The center of this northerly wind band also shifts eastward toward $120^{\circ} \mathrm{W}$ (the position of the northern part of the $\mathrm{CCV}$ ) as the time is approaching the onset, especially in Fig. 8. Those northerly winds are driving the cold air quickly down along the western coast, which helps to sustain the cold air anomaly (seen in Fig. 1), and the upper-air ridge (Fig. 6) also drives cold air southward above, so there is a thick layer of cold air that sustains the 500-hPa geopotential height trough.

As the SLP high centered over the continent moves southeastward on day -1 and the onset, the notable northerly wind band extends eastward to $90^{\circ} \mathrm{W}$ at lower levels in Fig. 7. As this sea level pressure high moves southeastward, there is also a noticeable southward shift of a deep layer of westerly winds that increase with height (Fig. 9). Behind is a deep layer of weak but persistent easterly winds (between two darker zero contours) that is leading (i.e., centered just south of) the lower troposphere coldest anomaly, visible on days -2 and -1 , becoming centered on the coldest anomaly at onset (and the next day). While coldest near the surface, the cold anomaly extends through a considerable depth. In the upper levels, the presence and the southward shift of these weak easterly winds is also consistent with the strengthening and southward expansion of the notable geopotential height trough over the western coast from day -2 to the onset in Fig. 6. As commented for Fig. 3, these easterly winds carry cold air westward into the 

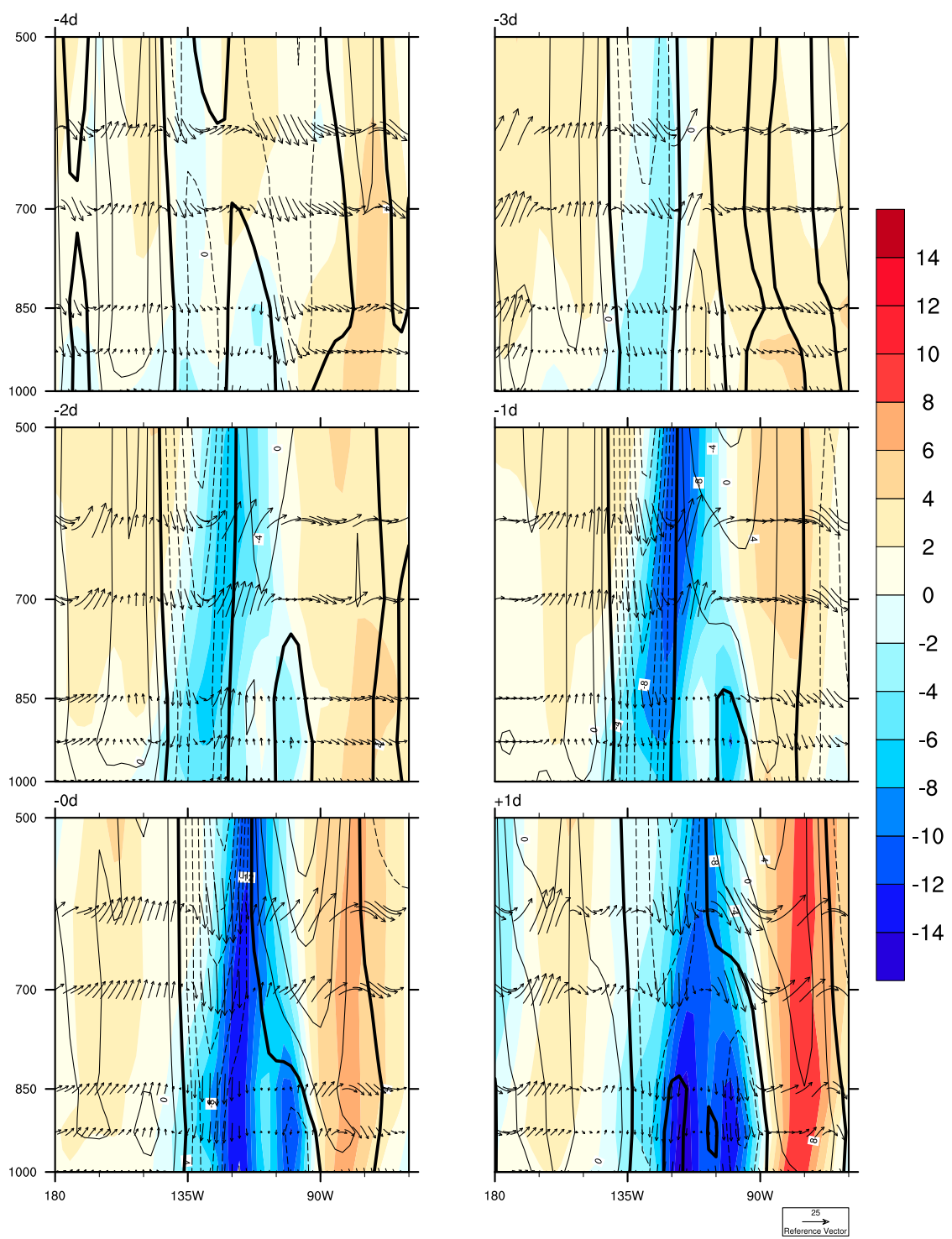

FIG. 7. Pressure-longitude cross section at $40^{\circ} \mathrm{N}$ for composite of the $10 \mathrm{CAOs}$. Color shading indicates temperature anomaly with an interval of $2 \mathrm{~K}$. Meridional wind is contoured; negative values have dashed contours, and positive values use solid contours; zero contours are indicated by thick solid lines; and contour interval is $4 \mathrm{~m} \mathrm{~s}^{-1}$. Vectors show zonal wind with minus pressure velocity components scaled to match the plot ranges. The reference value for pressure velocity is $0.1 \mathrm{~Pa} \mathrm{~s}^{-1}$. The labels $-N \mathrm{~d}$ and $+N \mathrm{~d}$ in the top-left corner of each panel denote $N$ days prior to and after onset, respectively (all times are at 1200 UTC). The northern part of the $\mathrm{CCV}$ is near about $120^{\circ} \mathrm{W}$ on these cross sections.

CCV. Figure 9 also shows the interplay between the positive vorticity advection aloft (inferred from the 500-hPa height anomaly shown in Fig. 6) and the cold air advection. The cold anomaly aloft leads the cold anomaly at the surface, leading to the 500 -hPa trough (Fig. 6) at $120^{\circ} \mathrm{W}$ being near $45^{\circ} \mathrm{N}$ on day -2 and $40^{\circ} \mathrm{N}$ on day -1 . Careful comparison of Figs. 9 and 6 reveals that the upper-level pressure trough has passed over the CCV from day -1 to onset, meaning that there is negative vorticity advection (or lessened positive advection) where there is also cold air advection, resulting in the very strong sinking at the cold anomaly seen from day -2 to the onset and beyond in Fig. 9. Sinking would cause some adiabatic warming which is consistent with at least part of the lessening cold anomaly after the onset. Again, the anomalies are with respect to local conditions so an anomaly migrating to a warmer region may have the same magnitude even as it adiabatically warms. 

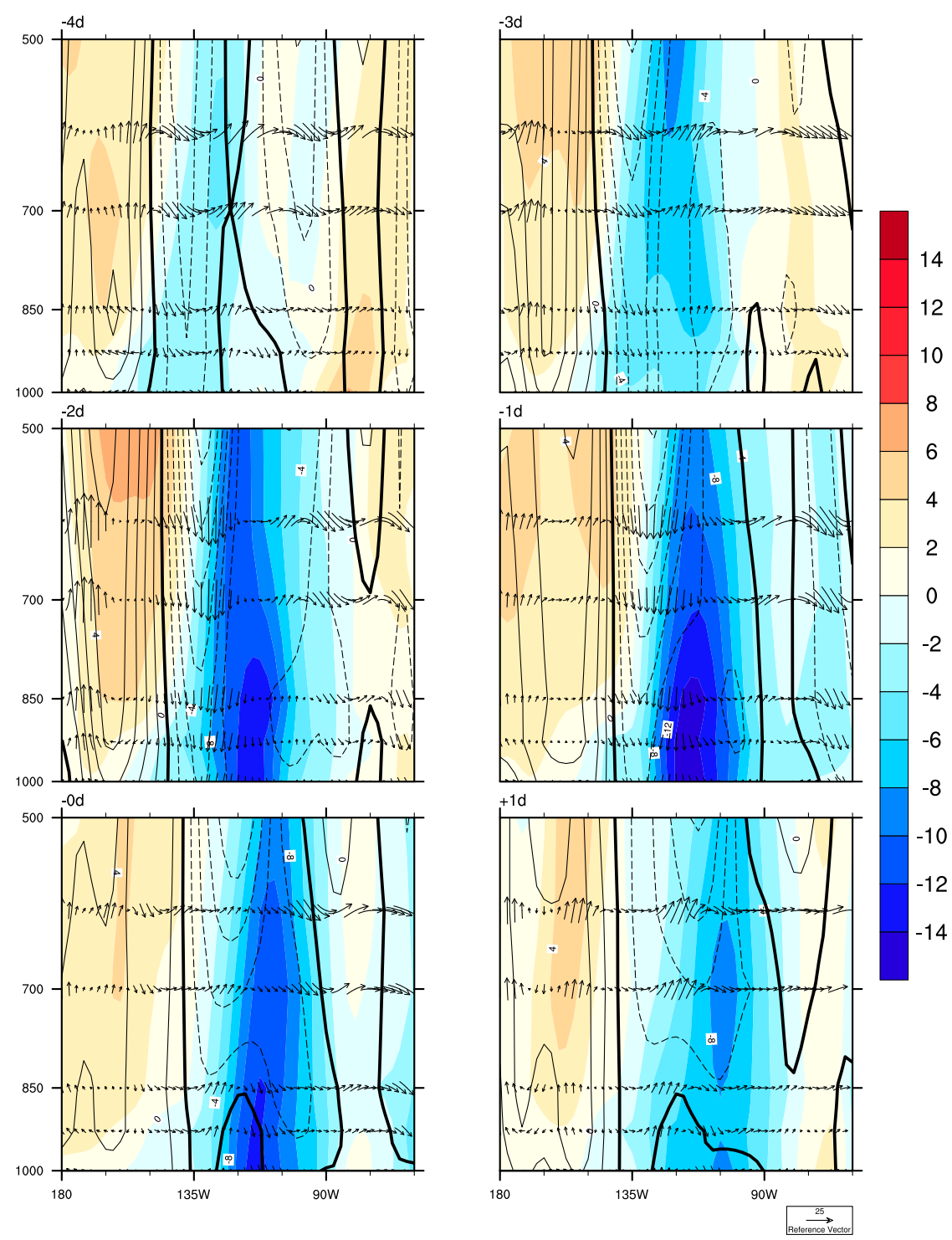

FIG. 8. As in Fig. 7, but at $50^{\circ} \mathrm{N}$.

In Fig. 8 (around $135^{\circ}-150^{\circ} \mathrm{W}$ ), there is a notable shallow cold air layer near the surface in the region of the oceanic SLP high with warm air anomaly above. This warm anomaly above the cold anomaly explains the unusual feature that the ridge in the middle and upper troposphere is nearly above the sea level pressure high.

Most of these synoptic properties associated with the CAOs in the CCV are quite large in spatial scale, much larger than the area of the CCV. In fact, the CAOs over the CCV also affect a much larger region, especially to the north of the CCV (Fig. 1).

\section{d. Backward trajectories}

Figure 10 shows the mean trajectories backward in time from two pressure levels above the $\mathrm{CCV}$ for each of the 10 events. As stated above, these mean trajectories for each event go back in time only as long as all the members of the mean trajectory follow a path within a specified distance from the mean (about twice the largest distance from the mean at the start). Here, all the trajectories go back about four days.

Near the onset, almost all events have trajectories in Fig. 10a coming to the CCV from at least $10^{\circ}$ latitude north of the CCV with one path arriving from the east side of the Rockies. Prior to that, half of them move monotonically, steadily sinking while traveling southward from farther north near or in the polar region (north of $60^{\circ} \mathrm{N}$ ), although some events have a starting point in the Pacific and different events have parcel trajectories moving at different speeds. This southward movement is 

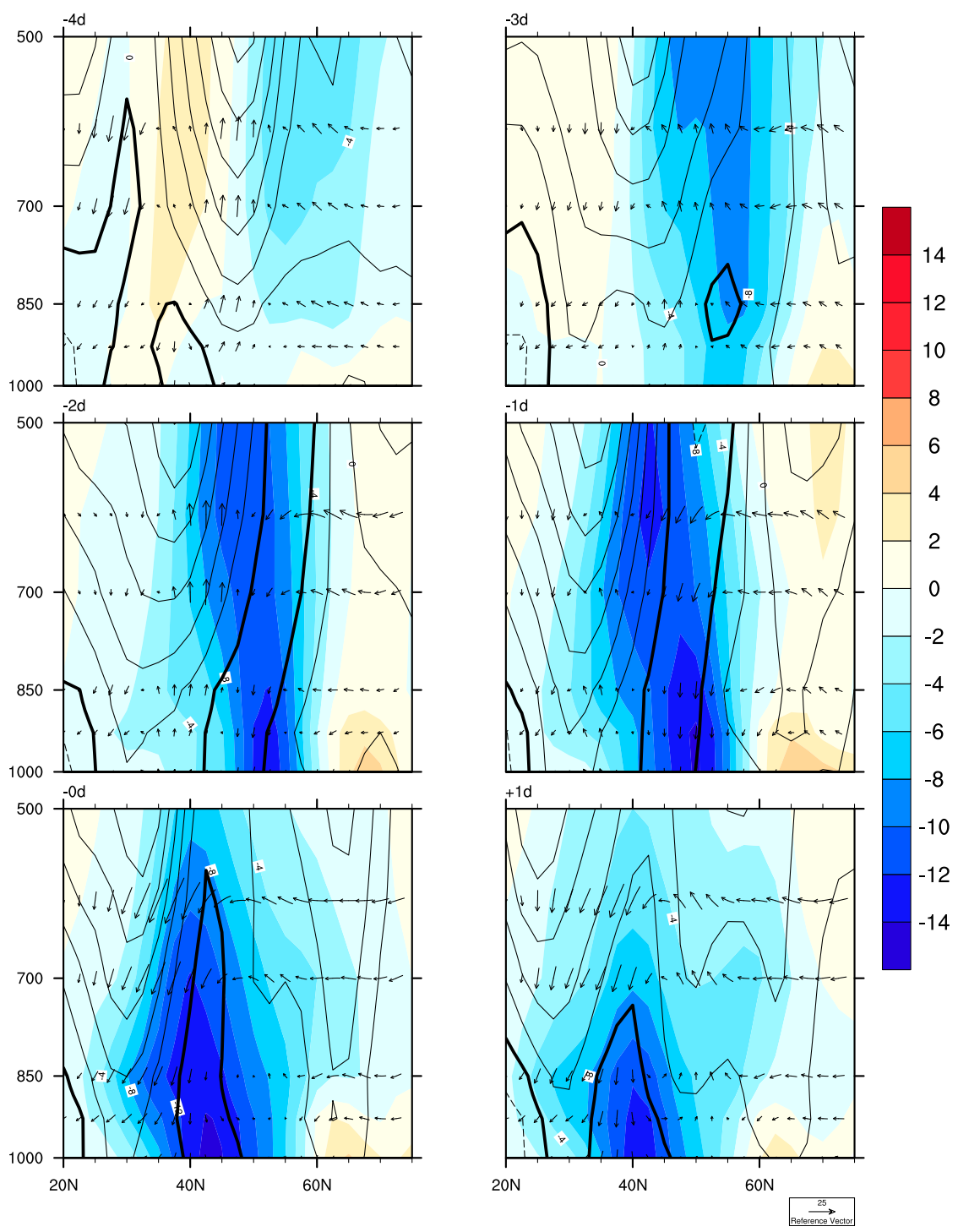

FIG. 9. Pressure-latitude cross section at $120^{\circ} \mathrm{W}$ for composites of the 10 CAOs. Color shading indicates temperature anomaly with an interval of $2 \mathrm{~K}$. Zonal wind is contoured; negative values (northerly winds) have dashed contours, and positive values use solid contours; zero contours are indicated by thick solid lines; and contour interval is $4 \mathrm{~m} \mathrm{~s}^{-1}$. Vectors show meridional wind with minus pressure velocity components scaled to match the plot ranges. The reference value for pressure velocity is $0.1 \mathrm{~Pa} \mathrm{~s}^{-1}$. The labels are as in Fig. 7 showing days prior to and after onset (all times are at $1200 \mathrm{UTC}$ ). The CCV is approximately between $35^{\circ}$ and $40^{\circ} \mathrm{N}$ latitude in the panels.

consistent with the movement of surface air temperature anomaly shown in Fig. 1, the winds seen in Figs. 3 and 7-9, and the implied cold air advection.

Eight of the 10 trajectories in Fig. 10a have an arc: moving eastward then curving toward the south, which is consistent with the 500-hPa ridge over the Alaskan region (trajectories 1 and 2 being exceptions over the time period calculated, although they trace the east side of that ridge). About half of the 10 trajectories travel offshore along the North American coast; they are quite high up when they do so they are not likely to be modified by marine interactions. Figure 3 shows that the surface winds over the ocean are parallel to these trajectories and quite strong near the coast. While several trajectories are just onshore, one is over the ocean (trajectory 5) but moves very quickly during the final $24 \mathrm{~h}$ and is also at a high altitude, and thus its modification by the ocean is likely limited. Several others (trajectories 1, 4, 8, 9, and 10) have a path across the Rockies during (at least) the last two days before onset and avoid crossing the ocean. 

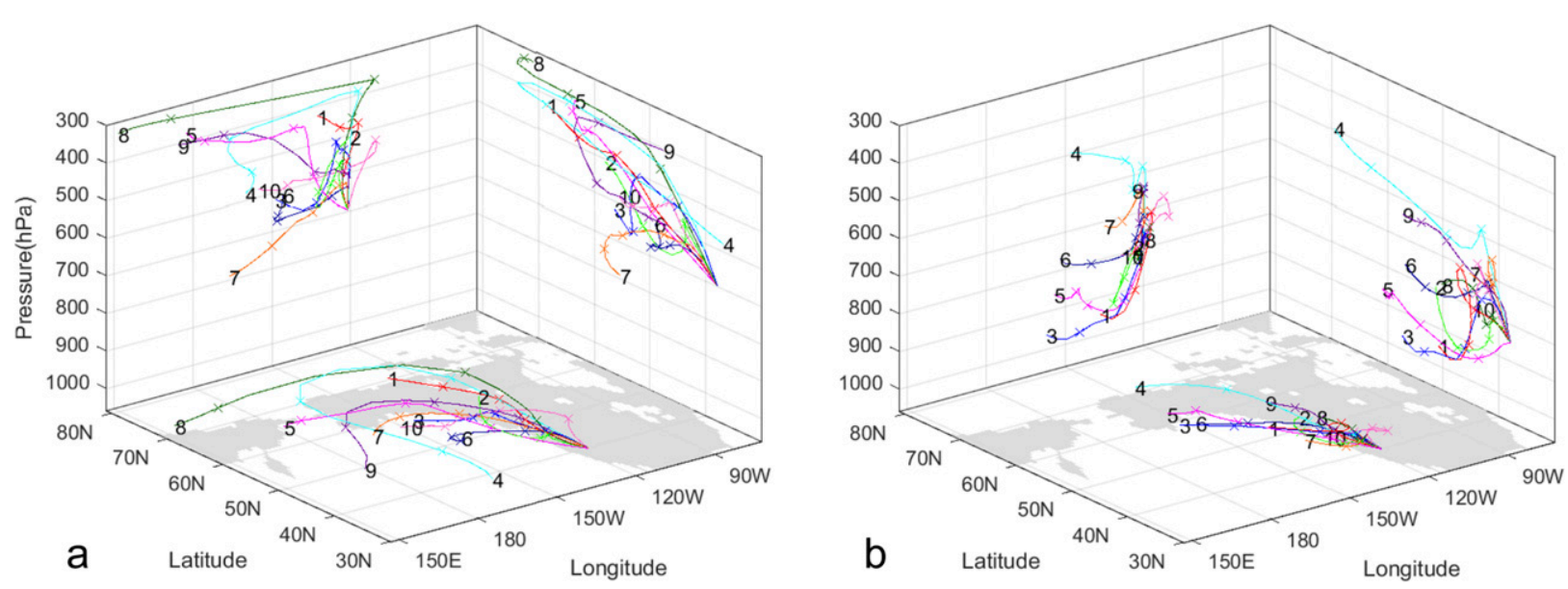

FIG. 10. Backward trajectories of the $10 \mathrm{CAOs}$ with projections onto latitude-pressure, longitude-pressure, and latitude-longitude planes trace back to about 4 days before the onset from (a) 700 and (b) $850 \mathrm{hPa}$. Trajectories shown are averages of six paths for each event, when the paths are consistent. Different events are shown with different colors. Events are labeled with numbers (Table 1) at the end of each trajectory. Every $24 \mathrm{~h}$ is marked by a cross along the trajectory. The gray area in the lat-lon plane indicates the land.

Near the onset, all events show sinking although some of them rise a little bit before the final sinking. Walsh et al. (2001) also found parcels sinking from the midtroposphere to near the surface in the cold air over the last few days prior to onset for CAOs affecting the eastern United States. Only one event in our study is followed backward to a point lower than $700 \mathrm{hPa}$ within four days. Sinking near the CCV is also seen in both the pressure-longitude cross section (Fig. 7, west of $120^{\circ} \mathrm{W}$ ) and the pressure-latitude cross section (Fig. 9, at or north of $40^{\circ} \mathrm{N}$ on day -1 and the onset). Not surprisingly, the trajectories tend to have a higher consistency near the onset (day -1) than days prior to that time.

The backward trajectories that start at $850 \mathrm{hPa}$ over the CCV (Fig. 10b) have notable differences from those arriving at $700 \mathrm{hPa}$. Three trajectories (events 1, 3, and 5) rise a lot while crossing the ocean. Two trajectories (events 4 and 9) have an arc path as found in Fig. 10a. About half of the 10 trajectories do not move very much compared with trajectories in Fig. 10a. Despite these differences of trajectories between two levels, several trajectories for $850 \mathrm{hPa}$ have a path along the coast similar to Fig. 10a. However, much of the western continent has a surface pressure lower than $850 \mathrm{hPa}$. So during our calculation of trajectories for $850 \mathrm{hPa}$, surface pressure and the corresponding wind fields are used many times [see step 8 in the description of the backward trajectories method in section 2.2.2 in Zhang (2016) for details].

As stated in the introduction, prior studies of the Canadian high in northwestern Canada suggested that there might be more than one type of CAO. Also, our prior work on heat waves found two ways that hot air reaches a region key to heat waves by following backward trajectories. So, one motivation for calculating backward trajectories was to see if two types of CCV CAOs could be identified. While there is much variation in the trajectories shown here we could find no systematic, unequivocal grouping of the events studied.

\section{Discussion and conclusions}

\section{a. Synoptic depiction}

The evolution of primary synoptic features before CAO onset is summarized as follows. The most consistent feature of the events is, obviously, the cold air anomaly over the CCV and much of the U.S. west coast at onset. Another feature common to all events is high SLP in the eastern Gulf of Alaska and farther south that has cold air on its east side being driven southeastward by strong northwesterly surface winds, especially just offshore. There is notable sinking of quite cold air on the east side of that SLP high associated with weak easterlies through the troposphere.

Backward trajectories provide a more intuitive depiction than the cross sections of the complex path followed by the cold air to reach the CCV at CAO onset (1200 UTC). Some trajectories that reach the lower troposphere above the CCV cross over ocean areas but are not modified because they are too high (none have pressures greater than $800 \mathrm{hPa}$ ). (A reviewer speculates that lower-level trajectories may move quickly enough over the ocean to be little modified, but we did not test this hypothesis.) There is much variation between trajectories in terms of the speed and level from which the 
cold air reaches $700 \mathrm{hPa}$ above the CCV. Most paths come from the middle to upper troposphere, although there are exceptions.

The high SLP over the continent includes a strong pressure gradient directed toward the CCV that should drive very cold air southwestward toward the CCV, although that flow is barely visible in the composites (Fig. 3). The timing of that easterly component over the land occurs sooner or later and over wider or narrower latitude ranges in the different events; contrary flows occur at other times, causing much cancellation in the composites.

All trajectories show strong sinking over the $\mathrm{CCV}$ in the final day or two as they approach the $\mathrm{CCV}$ at CAO onset. As they sink they warm by adiabatic compression. However, the cold anomaly (shown in cross sections) is preserved in at least three ways. First, the anomaly is locally defined, so a cold anomaly at a higher latitude of a given value could warm up adiabatically but still be an even stronger anomaly if it moves to a lower latitude that is climatologically much warmer. Second, the air parcels for most events diabatically cool as they approach the $700-\mathrm{hPa}$ (or $850 \mathrm{hPa}$ ) level above the CCV. Potential temperatures (not shown) of the air parcels change during the final two days; the amount varies between events from near $0^{\circ}$ to $10^{\circ} \mathrm{C}$ cooler. Third, since different events evolve in different ways, the common features in the patterns become more coincident as $\mathrm{CAO}$ onset is neared, thereby contributing to stronger anomalies closest to onset.

The unusual SLP high in and south of the Gulf of Alaska is crucial both to the development of unusual warmth over Alaska and to the flow of unusually cold air southeastward. High SLP over the continent in southwestern Canada drives interior cold air southwestward into the Pacific Northwest and California to reinforce the CCV CAOs. The cold anomaly in and south of the Gulf of Alaska has smaller magnitude than the cold air minimum over North America. The pattern and movement of the sea level pressure high over the continent are consistent with the movement of the surface cold anomalies and surface winds (Figs. 1-3). As this cold air anomaly expands over the west coast, it also expands the trough aloft westward. That trough aloft (and the midtropospheric cold air) is ahead (farther south in Fig. 9) of the near-surface cold air. Consequently, behind that trough is negative vorticity advection to reinforce the cold air advection in bringing the extreme cold to the CCV.

Pressure is the weight of all the air above a point. So, SLP rising requires an increase of mass. This might occur by colder, "more dense" air displacing warm air. This might occur with convergence aloft that is not fully balanced by divergence below, causing the air column to gain mass. On the east side of the SLP high strong cold air advection makes the air colder but the cold air advection also tends to force sinking motion. On the west side of the SLP high there is southerly motion, and warm air advection (WAA). The WAA builds an upper-level ridge (Fig. 6) and keeps building the eastern side of that ridge, which creates some negative vorticity advection (NVA). The WAA opposes the NVA forcing of vertical motion, so cross sections like Fig. 8 (days -1 and -2 ) show a transition to rising motion west of about $140^{\circ} \mathrm{W}$.

\section{b. LSMP context}

Highly significant LSMPs of temperature anomaly and geopotential height anomaly at onset have a strong warm ridge over the Bering Sea and western Alaska, another ridge over the southeastern United States, and a cold trough in between; these features are also seen in Grotjahn and Faure (2008). The statistical significance and the central extreme values of the LSMPs become larger as the time approaches the onset since the different events become more in phase. Also, the evolutions of the geopotential height anomalies at 500 and $1000 \mathrm{hPa}$ and temperature anomalies at $700 \mathrm{hPa}$ are consistent such that $700-\mathrm{hPa}$ temperature anomalies are a proxy of $1000-500-\mathrm{hPa}$ thickness. The LSMPs are an equivalent-barotropic, nearly stationary wave train (ridge-trough-ridge) across the North Pacific and North America. While this ridge-trough-ridge pattern looks qualitatively similar to the PNA loading pattern (with opposite sign) it is not the PNA pattern for several reasons, including the two largest amplitude centers of the PNA pattern being $>15^{\circ}$ latitude off from the LSMP. The North Pacific ridge expands northward in the composite and covers the whole Alaskan region with high significance (larger than $99.5 \%$ ) on day -3 . The highly significant ridge near the southeastern United States attains its maximum just before onset. The trough in between these two ridges develops on day -3 and continues to amplify toward the onset in the composite. While the characteristic LSMPs are seen in the composite, the patterns for individual events have notable variation until the final day or two (depending on the pattern element) before onset.

Meridional and zonal winds shown in cross sections help explain the evolution of the LSMP structures at various levels of the troposphere. The SLP low in the western North Pacific and the SLP high in and south of the Gulf of Alaska create a strong southerly component of surface winds in the central North Pacific. This southerly wind and associated positive temperature anomaly in longitude range of $180^{\circ}-150^{\circ} \mathrm{W}$ (Figs. 7 and 8 ) generates warm air advection in almost the whole layer of $500-1000 \mathrm{hPa}$ that builds the ridge near Alaska. The WAA through a large depth explains the equivalent-barotropic nature of the 
western ridge in the geopotential height LSMP. The warm anomaly above the shallow cold anomaly (Fig. 8) explains the unusual feature that the ridge in the middle and upper troposphere is mainly above the oceanic SLP high. The sinking occurs mainly along the east side of that oceanic SLP high where there is also a cold air anomaly. The cold anomaly is shallow over the west side and much deeper over the east side of the SLP high. The northerly winds near $120^{\circ} \mathrm{W}$ (Fig. 8) drive the cold air quickly along the western coast, which helps maintain the cold air anomaly (Fig. 1) and the upper-air ridge (Fig. 6) and drive cold air southward above so there is a thick layer of cold air to build the midtroposphere trough. A deep band of weak easterly winds in the pressure-latitude cross section (Fig. 9) moves southward and shows cold continental air moving into the $\mathrm{CCV}$.

In conclusion, the synoptic development of the LSMPs associated with CAOs is more complex than one might expect. It is not a simple pattern of cold air migrating from polar regions to the $\mathrm{CCV}$, even including displacement of that cold air by a ridge building over Alaska. Additional features, notably the unusual SLP high in and south of the Gulf of Alaska and contrasting surface and upper-air flows, bring the cold air to California. The rich complexity presents an interesting challenge to untangle with dynamical theory.

Acknowledgments. We thank Dr. Yun-Young Lee for her helpful discussions with us at the early stage of this work. This research was funded in part by NSF Grant 1236681 and NASA Grant NNX16AG62G and also supported by the USDA National Institute of Food and Agriculture, Hatch Project Accession No. 1010971. NCEP Reanalysis data were provided by the NOAA/ OAR/ESRL PSD, Boulder, Colorado, from their web site at http://www.esrl.noaa.gov/psd/. Station data were accessed from the University of California Statewide Integrated Pest Management portal: http://ipm.ucanr. edu/WEATHER/index.html. We thank the reviewers for helpful comments, including encouragement to mention the LSMP similarity to the PNA pattern.

\section{REFERENCES}

Carrera, M. L., R. W. Higgins, and V. E. Kousky, 2004: Downstream weather impacts associated with atmospheric blocking over the northeast Pacific. J. Climate, 17, 4823-4839, doi:10.1175/JCLI-3237.1.

Cassano, E. N., J. J. Cassano, and M. Nolan, 2011: Synoptic weather pattern controls on temperature in Alaska. J. Geophys. Res., 116, D11108, doi:10.1029/2010JD015341.

Cellitti, M. P., J. E. Walsh, R. M. Rauber, and D. H. Portis, 2006: Extreme cold air outbreaks over the United States, the polar vortex, and the large-scale circulation. J. Geophys. Res., 111, D02114, doi:10.1029/2005JD006273.
Colucci, S. J., and J. C. Davenport, 1987: Rapid surface anticyclogenesis: Synoptic climatology and attendant large-scale circulation changes. Mon. Wea. Rev., 115, 822-836, doi:10.1175/ 1520-0493(1987)115<0822:RSASCA > 2.0.CO;2.

Dallavalle, J. P., and L. F. Bosart, 1975: A synoptic investigation of anticyclogenesis accompanying North American polar air outbreaks. Mon. Wea. Rev., 103, 941-957, doi:10.1175/ 1520-0493(1975)103<0941:ASIOAA > 2.0.CO;2.

Dee, D. P., and Coauthors, 2011: The ERA-Interim reanalysis: Configuration and performance of the data assimilation system. Quart. J. Roy. Meteor. Soc., 137, 553-597, doi:10.1002/qj.828.

Feldstein, S. B., 2000: The timescale, power spectra, and climate noise properties of teleconnection patterns. J. Climate, 13, 4430-4440, doi:10.1175/1520-0442(2000)013<4430: TTPSAC $>2.0 . \mathrm{CO} ; 2$.

- 2002: Fundamental mechanisms of PNA growth and decay. Quart. J. Roy. Meteor. Soc., 128, 775-796, doi:10.1256/ 0035900021643683.

Grotjahn, R., 2011: Identifying extreme hottest days from large scale upper air data: A pilot scheme to find California central valley summertime maximum surface temperatures. Climate Dyn., 37, 587-604, doi:10.1007/s00382-011-0999-z.

_ , and C.-H. Wang, 1989: On the source of air modified by ocean surface fluxes to enhance frontal cyclone development. Ocean-Air Interact., 1, 257-288.

—_, and G. Faure, 2008: Composite predictor maps of extraordinary weather events in the Sacramento California region. Wea. Forecasting, 23, 313-335, doi:10.1175/ 2007WAF2006055.1.

__ , and Coauthors, 2016: North American extreme temperature events and related large scale meteorological patterns: A review of statistical methods, dynamics, modeling, and trends. Climate Dyn., 46, 1151-1184, doi:10.1007/ s00382-015-2638-6.

Hartmann, B., and G. Wendler, 2005: The significance of the 1976 Pacific climate shift in the climatology of Alaska. J. Climate, 18, 4824-4839, doi:10.1175/JCLI3532.1.

Kalnay, E., and Coauthors, 1996: The NCEP/NCAR 40-Year Reanalysis Project. Bull. Amer. Meteor. Soc., 77, 437-471, doi:10.1175/1520-0477(1996)077<0437:TNYRP>2.0.CO;2.

Konrad, C. E., 1996: Relationships between the intensity of cold-air outbreaks and the evolution of synoptic and planetary-scale features over North America. Mon. Wea. Rev., 124, 1067-1083, doi:10.1175/1520-0493(1996)124<1067:RBTIOC>2.0.CO;2. , 1998: Persistent planetary scale circulation patterns and their relationship with cold air outbreak activity over the eastern United States. Int. J. Climatol., 18, 1209-1221, doi:10.1002/ (SICI)1097-0088(199809)18:11<1209::AID-JOC301>3.0.CO;2-K.

_ air outbreaks over eastern North America. Mon. Wea Rev., 117, 2687-2700, doi:10.1175/1520-0493(1989)117<2687: AEOECA $>2.0 . C O ; 2$.

Lee, Y.-Y., and R. Grotjahn, 2016: California Central Valley summer heat waves form two ways. J. Climate, 29, 1201-1217, doi:10.1175/JCLI-D-15-0270.1.

Loikith, P. C., and A. J. Broccoli, 2012: Characteristics of observed atmospheric circulation patterns associated with temperature extremes over North America. J. Climate, 25, 7266-7281, doi:10.1175/JCLI-D-11-00709.1.

$\longrightarrow$, and - 2014: The influence of recurrent modes of climate variability on the occurrence of winter and summer extreme temperatures over North America. J. Climate, 27, 1600-1618, doi:10.1175/JCLI-D-13-00068.1. 
B. R. Lintner, and A. Sweeney, 2017: Characterizing largescale meteorological patterns and associated temperature and precipitation extremes over the northwestern United States using self-organizing maps. J. Climate, 30, 2829-2847, doi:10.1175/JCLI-D-16-0670.1.

Portis, D. H., M. P. Cellitti, W. L. Chapman, and J. E. Walsh, 2006: Low-frequency variability and evolution of North American cold air outbreaks. Mon. Wea. Rev., 134, 579-597, doi:10.1175/ MWR3083.1.

Quadrelli, R., and J. M. Wallace, 2004: Varied expressions of the hemispheric circulation observed in association with contrasting polarities of prescribed patterns of variability. J. Climate, 17, 4225-4253, doi:10.1175/JCLI3196.1.

Vavrus, S., J. E. Walsh, W. L. Chapman, and D. Portis, 2006 The behavior of extreme cold air outbreaks under greenhouse warming. Int. J. Climatol., 26, 1133-1147, doi:10.1002/ joc.1301.

Walsh, J. E., A. S. Phillips, D. H. Portis, and W. L. Chapman, 2001: Extreme cold outbreaks in the United States and Europe, 1948-99. J. Climate, 14, 2642-2658, doi:10.1175/ 1520-0442(2001)014<2642:ECOITU > 2.0.CO;2.

Westby, R. M., and R. X. Black, 2015: Development of anomalous temperature regimes over the southeastern United States:
Synoptic behavior and role of low-frequency modes. Wea. Forecasting, 30, 553-570, doi:10.1175/WAF-D-14-00093.1.

Whan, K., and F. W. Zwiers, 2016: Evaluation of extreme rainfall and temperature over North America in CanRCM4 and CRCM5. Climate Dyn., 46, 3821-3843, doi:10.1007/ s00382-015-2807-7.

_, _ _ and J. Sillmann, 2016: The influence of atmospheric blocking on extreme winter minimum temperatures in North America. J. Climate, 29, 4361-4381, doi:10.1175/ JCLI-D-15-0493.1.

Wheeler, D. D., V. L. Harvey, D. E. Atkinson, R. L. Collins, and M. J. Mills, 2011: A climatology of cold air outbreaks over North America: WACCM and ERA-40 comparison and analysis. J. Geophys. Res., 116, D12107, doi:10.1029/2011JD015711.

Xie, Z., R. X. Black, and Y. Deng, 2017: The structure and largescale organization of extreme cold waves over the conterminous United States. Climate Dyn., doi:10.1007/ s00382-017-3564-6, in press.

Zhang, R., 2016: Synoptic and dynamical analysis of cold air outbreaks over California Central Valley. M.S. thesis, Department of Land, Air and Water Resources, University of California Davis, 62 pp., grotjahn.ucdavis.edu/EWEs/ Thesis_RZ_2016Dec.pdf. 